\title{
EFFECTS OF MAGNETIC SATURATION ON INDUCTION MACHINES DRIVEN BY STATIC CONVERTERS
}

\author{
Darizon A. de Andrade* \\ Marcos A. A. de Freitas ${ }^{\dagger}$ \\ Luciano M. Neto* \\ Hélder de Paula*
}

\author{
José L. Domingos ${ }^{\ddagger}$ \\ *FEELT-UFUCaixa Postal 2160 CEP 38.400-902 - Uberlândia - MG \\ $\dagger^{\dagger}$ FEIT-UEMGCaixa Postal 431 CEP 38.302-192 - Ituiutaba - MG \\ ${ }^{\ddagger}$ CEFET/GORua 75, Nr. 46, CentroCEP 74.055-110 - Goiânia - GO
}

\begin{abstract}
The effects of magnetic saturation on the operation of induction motors driven by static converters are analyzed. A mathematical model based on magnetic harmonic functions is used to account for saturation. Distortions on the air gap flux due to non-linear magnetic characteristics lead to appearance of space harmonics in the resultant flux density distribution. This causes specific distortions in stator and rotor time quantities, which are different from those due to static converter. Operation with six pulse and sinusoidal PWM converters under saturated conditions is considered. Comparisons of experimental and simulated results are presented and found to be in very good agreement.
\end{abstract}

KEYWORDS: Induction Machine Drive, Magnetic Saturation.

\section{RESUMO}

Neste trabalho são analisados os efeitos da saturação

Artigo submetido em $04 / 10 / 02$

1a. Revisão em 25/11/02; 2a. Revisão em 19/05/03

Aceito sob recomendação do Ed. Assoc. Prof. José A. Pomilio magnética na operação de motores de indução, quando acionados por conversores estáticos. Para estudos de simulação um modelo matemático baseado em funções harmônicas magnéticas é utilizado para levar em conta a saturação. Observa-se que distorções no fluxo de entreferro devido às características magnéticas não lineares resultam em harmônicos espaciais na distribuição da densidade de fluxo resultante. Estes por sua vez, causam distorções nas grandezas temporais de estator e rotor, diferentes daquelas devido ao conversor estático. A operação do motor em condições de saturação é analisada para conversores de seis pulsos e PWM senoidal. A comparação dos resultados experimentais com os simulados mostrou ótima concordância.

PALAVRAS-CHAVE: Máquinas de indução, modelagem matemática, saturação magnética, acionamento estático.

\section{INTRODUCTION}

Induction machines driven by static converters are widespread in the industry. The majority of works found in literature neglect the effects of magnetic saturation and air gap spatial flux harmonics, limiting the 
study to superficial analyses. Due to the non-linear relation between flux and magnetizing current, either dq or phase quantities based models lead to inaccurate and uncertain results under several operation characteristics (Levi, 1994). A great number of papers is focused on the development of mathematical models for a suitable representation of the magnetic saturation effects. Thus, many modeling techniques, with different alternatives to account for such effects, have been proposed. These techniques are based mainly on the election of the state variables (Levi 1996a and 1996b), small-signal models (Melkebeek et al., 1983) and modifications in the machine equivalent circuit (Moreira et al., 1992 and Liao et al., 1994). Some works analyze the machine behavior when it is driven by vector-controlled converters, taking into account the magnetic saturation. However, the analyses are limited to steady-state conditions and only the air-gap fundamental flux component is considered (Khater et al., 1987 and Ojo et al., 1994). In Moreira et al.(1992) and Liao, et al. (1994), the influence of spatial harmonics is considered. A modified dq model is developed where the saturation is included through the consideration of a variable air-gap length, which is a function of saturation level and spatial position. The analysis presented refers only to the star connection, and the third spatial harmonic is incorporated by the insertion of fictitious windings, thus modifying the machine equivalent circuit.

The aim of this paper is to offer a contribution to the topic induction machines driven by static converters, taking into account the effects of magnetic saturation and spatial flux harmonics. By using a suitable mathematical model, saturation is accounted for and the paper presents an analysis of static converter-fed saturated induction-machines. Experimental and simulated results are obtained and analyzed, leading to important conclusions about drive operation.

\section{MATHEMATICAL MODELING}

The mathematical model uses a phase quantity based modeling approach, developed by Bispo et al. (2001), Neto et al. (1999a and 1999b) and Resende et al. (1999), using the concept of harmonic magnetic function. The total phase flux linkages are taken as state variables. There is no use of variable transformations as commonly used in other works in order to represent the crosssaturation. The effects of the 3rd spatial harmonics are considered without any manipulation in the equivalent circuit and with no requirement for the machine design data. Only the knowledge of machine terminal quantities are required to quantify the saturation. Quantities are determined in their own referential, providing a better physical insight about their behavior. Although the final equations to implement the model come out very simple, the full development is quite involved and is explained in detail in the above references. Following, a simple description aiming to give a background idea of the modeling is presented.

Considering a generic phase $n$ that represents a stator or rotor phase, and neglecting the machine iron losses, the motor voltage equation is given by

$$
V_{n}=R_{n} i_{n}+\frac{d \lambda_{n}}{d t}
$$

where $V_{n}, R_{n}, i_{n}$ e $\lambda_{n}$ are the voltage, resistance, current and total flux linkage of the phase $n$, respectively.

Assuming the leakage flux as linear, the total phase flux linkage is calculated by

$$
\lambda_{n}=L_{n} i_{n}+\lambda_{m n} \quad \Rightarrow \quad i_{n}=\frac{\lambda_{n}-\lambda_{m n}}{L_{n}}
$$

where $L_{n}$ and $\lambda_{m n}$ are the leakage inductance and magnetizing flux of phase $n$.

Since $V_{n}$ and $R_{n}$ are known, the solution of (1) is possible using the relation between $i_{n}$ and $\lambda_{n}$ given by (2), provided $\lambda_{m n}$ is known. In order to obtain the phase flux linkage, only the fundamental component of the resultant spatial distribution of magnetomotive force produced by the currents of all rotor and stator phases is considered.

Suppose that the maximum value $(F M)$ of this spatial distribution is located at a position given by an angle $\alpha$, at a certain instant of time, defined in a $\theta$ reference axis of which origin is coincident with the phase $a$ winding axis (figure 1). The distribution of magnetomotive force is written as

$$
\begin{aligned}
& m m f(\theta)=F M \cos (\theta-\alpha)= \\
& \sum_{n=a, b, c, A, B, C} 2 K_{n} i_{n} \cos \left(\theta-\theta_{n}\right)
\end{aligned}
$$

where

$F M$ - amplitude of the spatial distribution of magnetomotive force;

$\theta$ - angular displacement along the reference axis;

$K_{n}$ - winding factor of rotor and stator phases $(a, b, c$, $A, B, C)$;

$\theta_{n}$ - generic position of the rotor and stator phases $\left(\theta_{a}, \theta_{b}, \theta_{c}, \theta_{A}, \theta_{B}, \theta_{C}\right)$ 
$\alpha$ - angular position of the m.m.f peak.

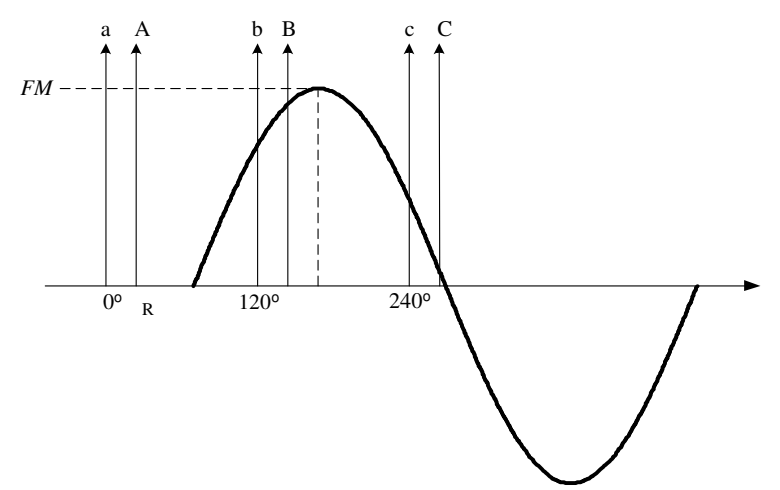

Figure 1: Spatial Distribution of the Magnetomotive Force.

The m.m.f $(\theta)$ produces a resultant distribution of magnetic flux density $B(\theta)$. Regarding the magnetizing curve which characterizes the machine magnetic circuit, the m.m.f $(\theta)$ distribution produces a non-sinusoidal $B(\theta)$, but still symmetric in relation to the m.m.f $(\theta)$ axis.

The application of Fourier analysis leads to

$$
B(\theta)=\sum_{h=1,3} B_{h} \cos [h(\theta-\alpha)]
$$

where

$B_{h}$ - maximum value of the $h^{\text {th }}$ component of $B(\theta)$;

$h$ - harmonic order.

Considering the winding of phase $n$ distributed in several coils, each one with $N$ turns, of which central axis is situated at a $\theta_{n}$ position (figure 3 ), the total flux linking

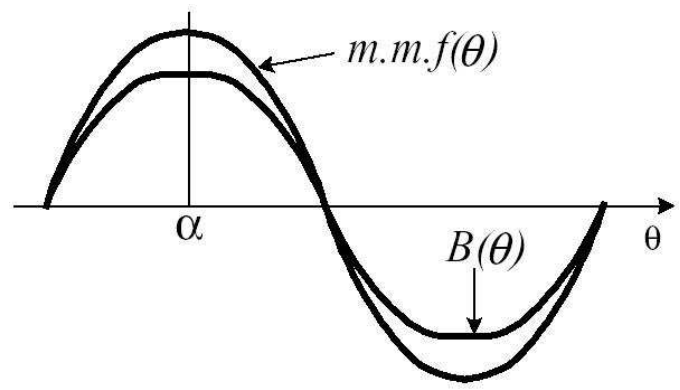

Figure 2: Resultant spatial Distribution of Flux Density $\mathrm{B}(\theta)$ the winding due to $B(\theta)$ is

$$
\lambda_{m n}=\sum_{h=1,3} F_{h}(\overline{F M}) \cos \left[h\left(\alpha-\theta_{n}\right)\right]
$$

where $F_{h}(\overline{F M})$ is the "magnetic harmonic function". It is obtained experimentally.

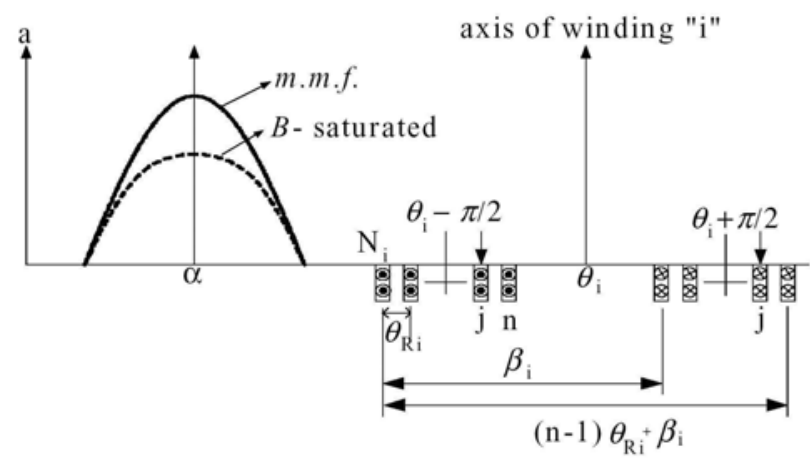

Figure 3: Distribution of (m.m.f( $\theta)$, Flux Density and Winding.

Manipulating (2), (3) and (5) as shown by Bispo et al. (2001), the following equations arise

$$
\begin{aligned}
f_{R}(\lambda) & =\sum_{n=a, b, c, A, B, C} \frac{\lambda_{n}}{L_{n}} \cos \left(\theta_{n}\right) \\
f_{I}(\lambda) & =\sum_{n=a, b, c, A, B, C} \frac{\lambda_{n}}{L_{n}} \sin \left(\theta_{n}\right) \\
f(\lambda) & =\sqrt{\left[f_{R}(\lambda)\right]^{2}+\left[f_{I}(\lambda)\right]^{2}} \\
t g(\alpha) & =\frac{f_{I}(\lambda)}{f_{R}(\lambda)} \\
F_{1}(\overline{F M}) & =\frac{f(\lambda)}{A_{S}}-\frac{\overline{F M}}{A_{S}} \\
A_{S} & =\frac{3}{2}\left(\frac{1}{L_{s}}+\frac{1}{L_{r}}\right)
\end{aligned}
$$

where $L_{s}$ and $L_{r}$ are the leakage inductances of stator and rotor respectively. Equations (1) to (11) comprise the motor model.

The solution is as follows: from a numerical integration method, (1) is solved. For each integration step, $V_{n}$ and $\lambda_{n}$ are known. From $(6)-(8), f(\lambda)$ is calculated; $A_{s}$ is determined in (11). Knowing the magnetic function $F_{1}(\overline{F M}), f(\lambda)$ and $A_{s}$, a line equation is defined by (10). The intersection of this line with the magnetizing curve defines the values of $F_{1}(\overline{F M})$ and $\overline{F M}$ in each integration step. The value of $F_{3}(\overline{F M})$ is calculated by means of numerical interpolation with $F_{1}(\overline{F M})$. 
The harmonic magnetic functions $F_{1}(\overline{F M})$ and $F_{3}(\overline{F M})$ are determined experimentally driving the induction machine at synchronous speed. Different values of balanced and distortion-free three-fase voltage are applied to the stator and the instantaneous values of $V_{n}$ and $i_{n}$ are digitally stored. This current corresponds to excitation current. Taking the iron losses out of the measured current and using the machine parameters, the instantaneous values of the magnetizing flux using (1) and (2) are determined. Fourier analysis provides $F_{1}(\overline{F M})$ and $F_{3}(\overline{F M})$ (figure 4 ), corresponding to the amplitude of its fundamental and third harmonic components.
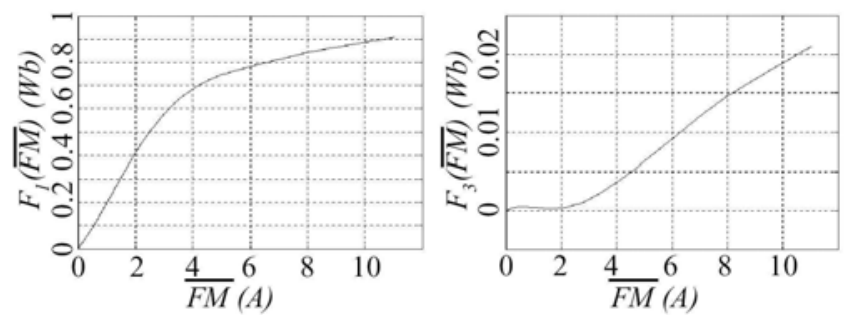

Figure 4: Curves Experimentally Obtained: $F_{1}$ vs $(\overline{F M}) ;(\mathrm{b}) F_{1}$ vs $(\overline{F M})$.

(a)

\section{SIMULATION RESULTS}

Some simulations were performed in order to verify the behavior of the machine supplied by six step and sinusoidal PWM converters. Analyses were carried for both star and delta winding connections, with the motor at no-load. Initially, the results are presented considering a linear magnetic circuit; in the sequence, the effects of the saturation and spatial 3rd harmonic of the air-gap flux are included. In the non-saturated condition, that is, considering the machine magnetic circuit linear, the air gap flux varies linearly with the magnetizing current (figure 2).

\subsection{Six-step motor drive}

Figures 5 and 6 show results of simulation considering linear magnetic circuit for the machine. Line and phase currents are shown for the delta connection under six-step driving in Figure 5. Figure 6 shows the phase voltage and line current for the six-step drive with machine windings connected in star. The presentation of results along the paper is structured such as to show the corresponding frequency spectrum of the waveform under analysis. As expected from the analysis with linear magnetic circuit, only the harmonics originated by the switching strategy are present in the waveforms, which in the case of six-step drive correspond to 5 th, 7 th, 11th

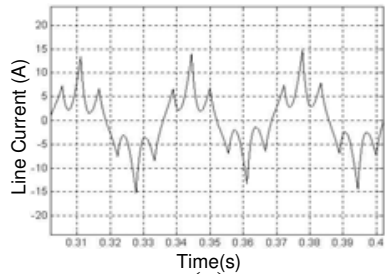

(a)

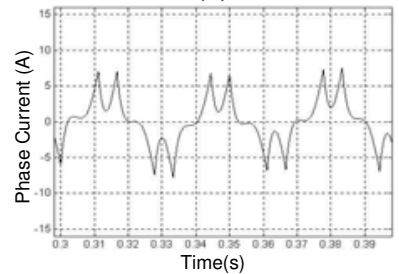

(c)

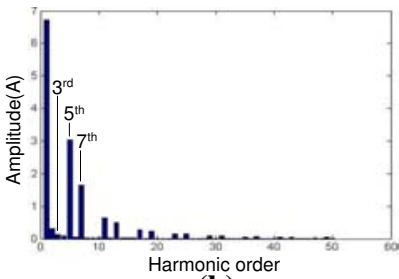

(b)

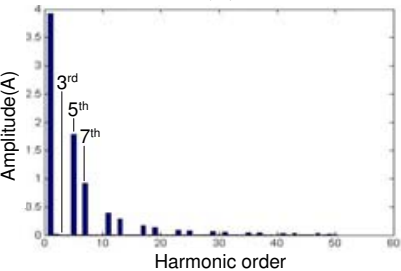

(d)
Figure 5: Results for delta connection. (a) Line Current; (b) Frequency Spectrum; (c) Phase Current; (d) Frequency Spectrum.

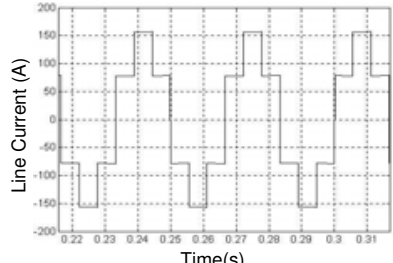

(a)

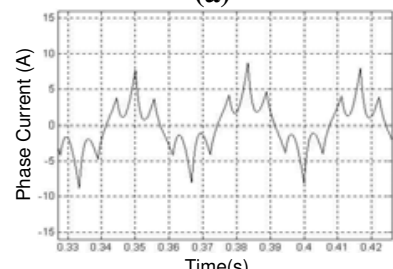

(c)

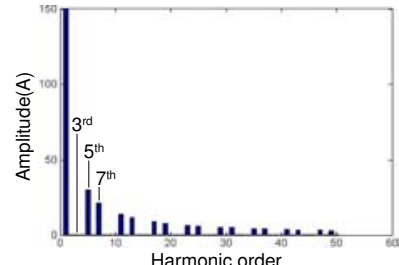

(b)

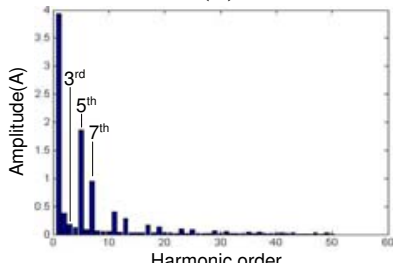

(d)
Figure 6: Results for star connection. (a) Phase Voltage; (b) Frequency Spectrum; (c) Line Current; (d) Frequency Spectrum.

and 13th ... harmonics.

Following, the behavior of the machine considering saturation is studied for the six-step drive. Figure 7 shows the phase current for delta connection. Compared with figures $5 \mathrm{c}-5 \mathrm{~d}$ it is noticed the presence of third harmonic in this current besides the harmonics due to electronic converter. The saturation of the air gap flux is the responsible for this harmonic component in the phase current. Turning to star connection, figure 8 , the effect of saturation will lead to distortion in the phase voltage, observed by the "rounding" of the stepped waveform. 


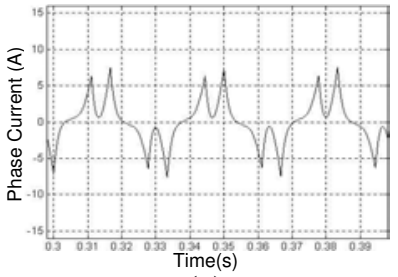

(a)

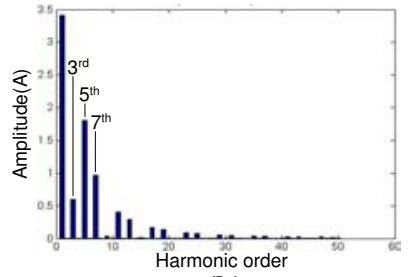

(b)
Figure 7: Results for delta connection. (a) Phase Current; (b) Frequency Spectrum.
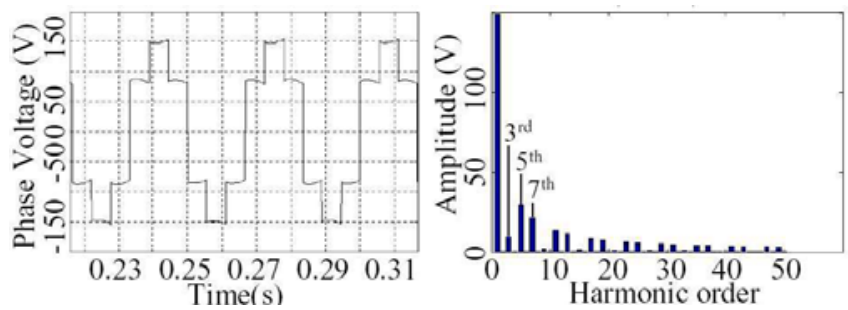

Figure 8: Results for star connection. (a) Phase Voltage; (b) Frequency Spectrum.

Comparison of figures 8 and $6 \mathrm{a}-6 \mathrm{~b}$ show the difference caused by the presence of third harmonic in this waveform. It is important to observe that, as expected, the line currents for both star and delta connection do not show any distortion caused by the third harmonic component of air-gap flux either for delta or star connection.

\subsection{Sinusoidal PWM motor drive}

Simulations were also conducted with the machine being fed by a sinusoidal PWM converter. As before, first the results for delta and star connections taken from linear magnetic circuit modeling are shown, and in the sequence those corresponding to saturated machine model are placed for comparison.

Figure 9 shows the line and phase current for delta connection and figure 10 shows the phase voltage and line current for star. As noticed, the PWM switching leads to improved waveforms, with negligible presence of low order harmonics.

With simulation including the effects of saturation, the phase currents for delta will show the distortions caused by the non-linearity of the magnetic circuit, which is confirmed by the corresponding frequency spectrum as seen in figure 11. For the star connection case, the distortion is caused in the phase voltage as observed in figure 12 .

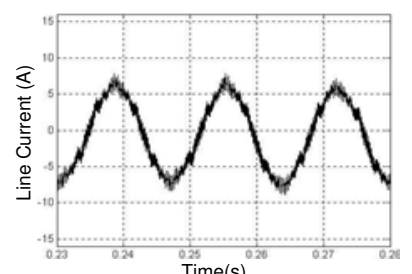

(a)

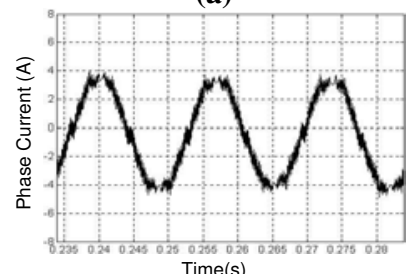

(c)

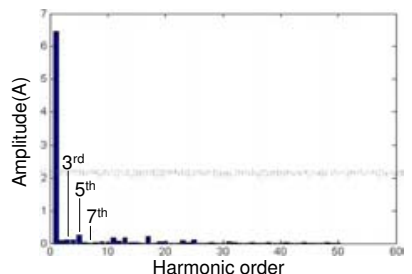

(b)

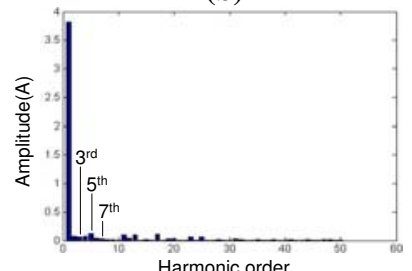

(d)
Figure 9: Results for delta connection. (a) Line Current; (b) Frequency Spectrum; (c) Phase Current; (d) Frequency Spectrum.

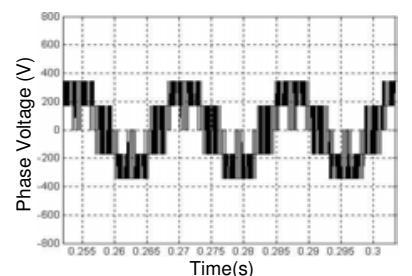

(a)

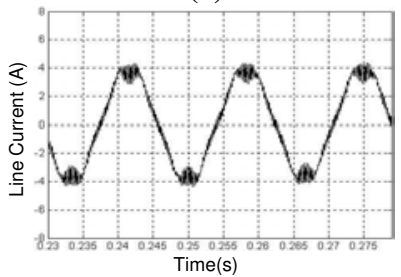

(c)

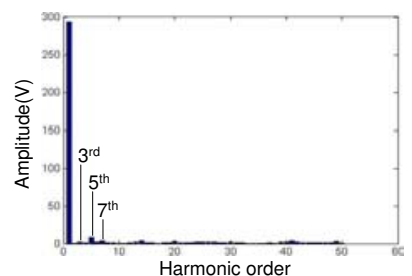

(b)

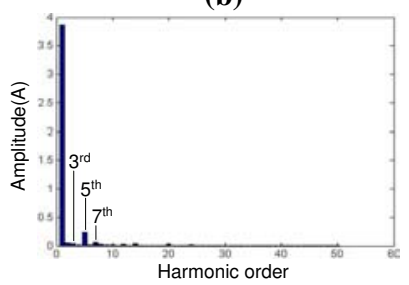

(d)
Figure 10: Results for star connection. (a) Phase Voltage; (b) Frequency Spectrum; (c) Line Current; (d) Frequency Spectrum.

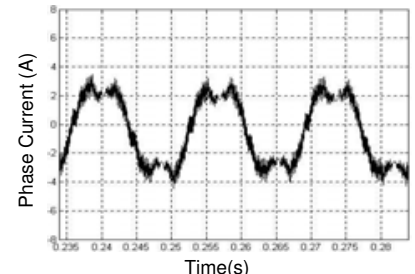

(a)

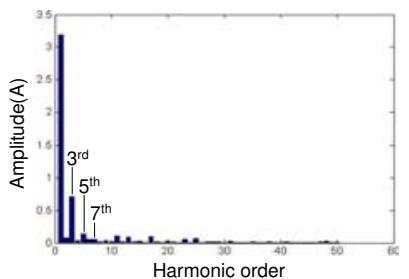

(b)
Figure 11: Results for delta connection. (a) Phase Current; (b) Frequency Spectrum. 

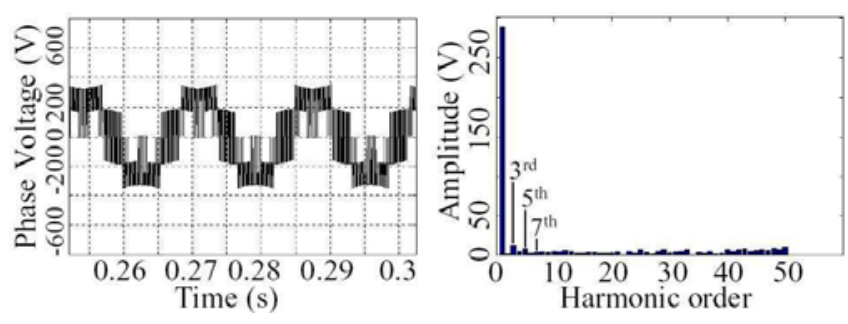

Figure 12: Results for star connection. (a) Phase Voltage; (b) Frequency Spectrum.

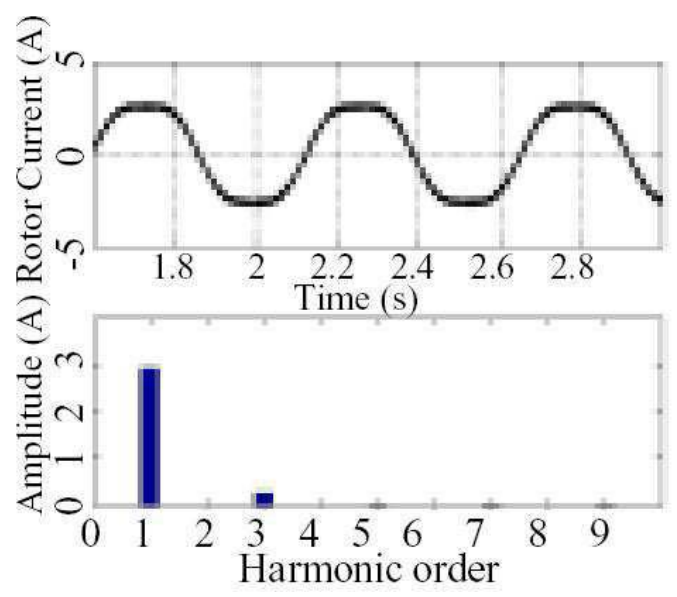

Figure 13: Rotor Current and Frequency Spectrum.

Rotor quantities, as well as the electromagnetic torque, will also be affected by the air-gap flux saturation. Figs. 13 and 14 show the simulated waveforms of the rotor current, its frequency spectrum and the steady-state electromagnetic torque. The "flattened" air gap flux wave induces distorted voltage in the rotor, which in turn establishes "flattened" rotor currents. Machine torque being the result of interaction of air-gap flux and rotor current spatial distributions will be affected resulting in low frequency oscillations as shown in Fig. 14.

Another situation analyzed is the operation with voltage boost. A voltage $20 \%$ greater than the rated $\mathrm{V} / \mathrm{f}$ value was supplied to the motor. This can occur in real cases when the stator voltage drop compensation for lower operation frequencies is excessive. In such situations, since the motor operates at a higher saturation level, the fundamental component of the stator current is increased, as well as the presence of the spatial third harmonic. The results are observed in figure 15. Comparing figures $15 \mathrm{a}-15 \mathrm{~b}$, that correspond to linear model, with figures $15 \mathrm{c}-15 \mathrm{~d}$, from the saturated model, one can note the higher value of fundamental component of current that occurs in the saturated condition (approximately

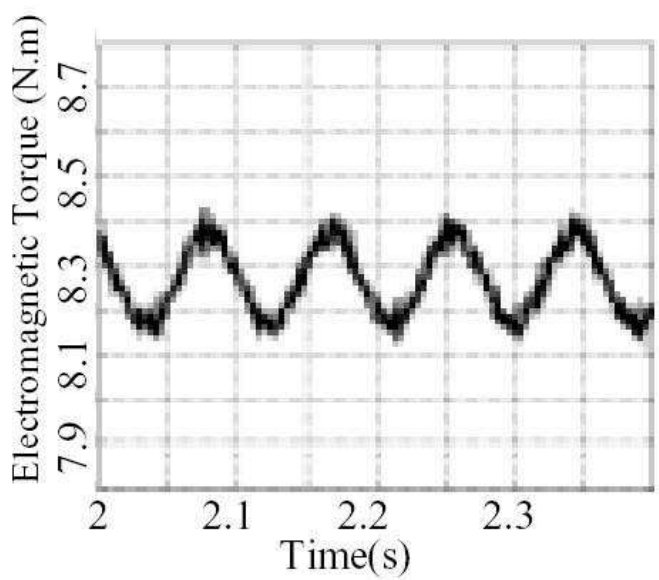

Figure 14: Eletromagnetic Torque.

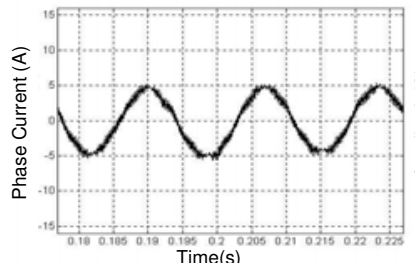

(a)

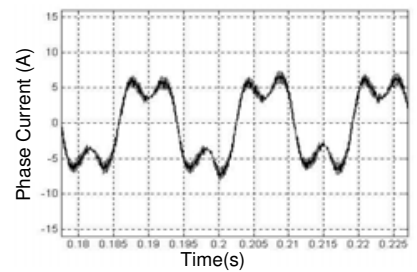

(c)

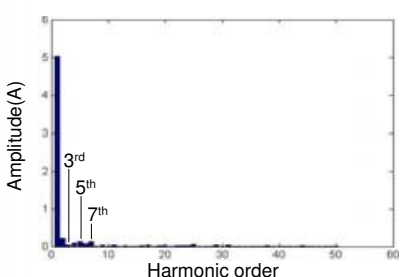

(b)

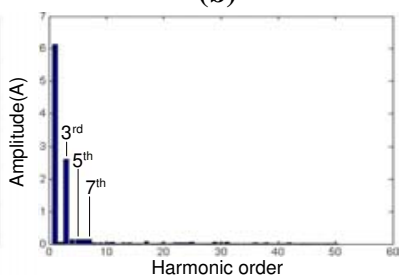

(d)
Figure 15: Phase current, delta connection. Operation with voltage boost - (a) Linear Model; (b) Frequency Spectrum; (c) Non-linear Model; (d) Frequency Spectrum.

$20 \%$ higher). This indicates a considerable error when using a linear model for this operation condition. Furthermore, the increased saturation leads to a stronger flattening in the flux distribution, which is reflected in higher third harmonic component in the phase current, as noticed in figure 15. Comparing with figure 11a, a threefold increase in the magnitude of the third harmonic is observed.

\section{EXPERIMENTAL RESULTS}

In order to confirm and validate the previous studies, experimental results with six-step and sinusoidal PWM modulation techniques are shown in the following. The 


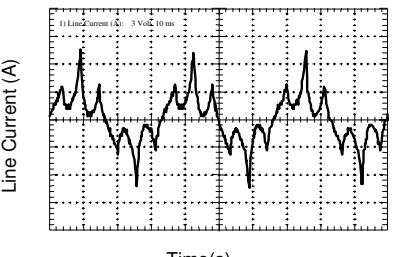

Time(s)
(a)

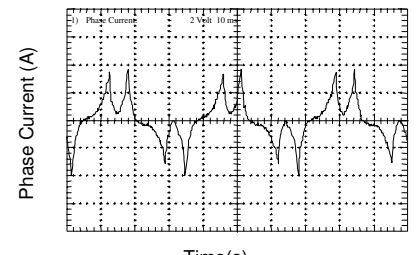

(c)

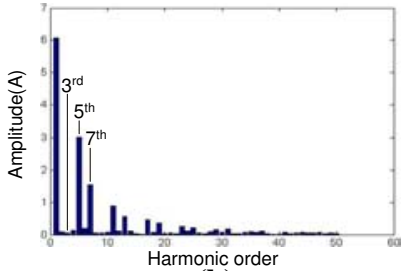

(b)

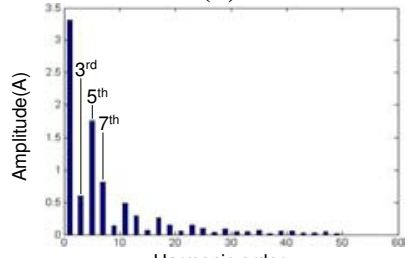

(d)

Figure 16: Results for delta connection. (a) Line Current; (b) Frequency Spectrum; (c) Phase Current; (d) Frequency Spectrum.

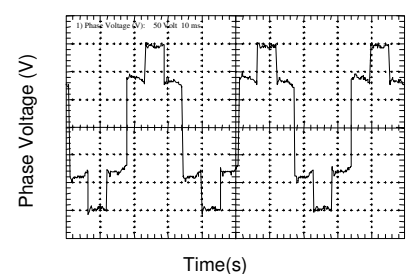

(a)

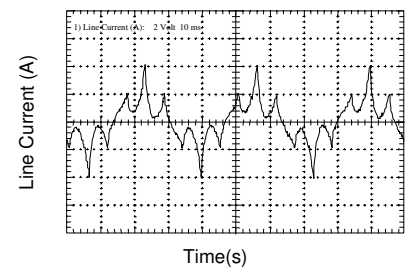

(c)

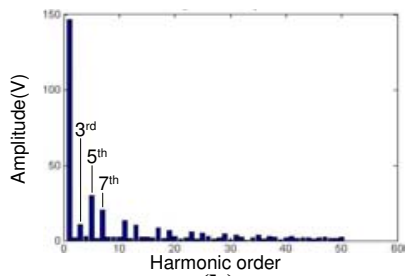

(b)

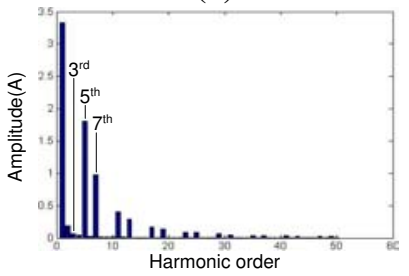

(d)

Figure 17: Results for star connection. (a) Phase Voltage; (b) Frequency Spectrum; (c) Line Current; (d) Frequency Spectrum.

motor is driven at no-load. A six-step converter with IGBT module was built in the laboratory for experiments. PWM modulation driving was realized with a commercial converter.

\subsection{Six-step motor drive}

Figure 16 presents the voltage and six-stepped line and phase currents waveforms for the delta-connected motor. It is observed that the results are in very good agreement with those originated by simulation. As expected, the

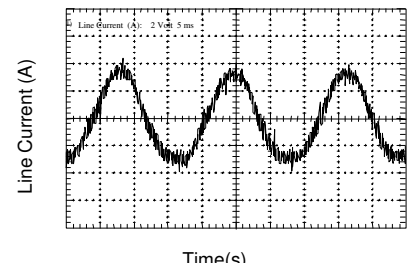

Time(s)
(a)

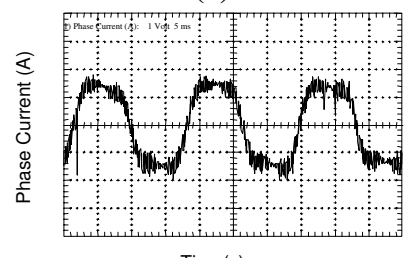

(c)

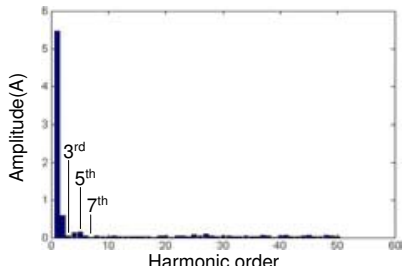

(b)

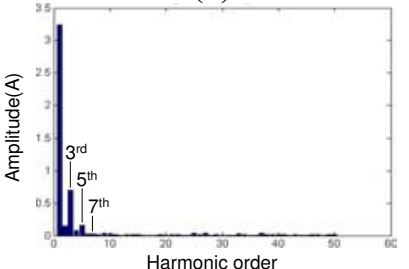

(d)
Figure 18: Results for delta connection. (a) Line Current; (b) Frequency Spectrum; (c) Phase Current; (d) Frequency Spectrum.

third harmonic is present in the phase current, as confirmed by the frequency spectrum. Phase voltage and line current from star-connected operation are shown in figure 17. The "rounded" shape indicated by the simulation is confirmed in this measurement, and the amount of third harmonic present due to saturation is indicated in the waveform frequency spectrum.

Phase voltage and line current from star-connected operation are shown in figure 17. The "rounded" shape indicated by the simulation is confirmed in this measurement, and the amount of third harmonic present due to saturation is indicated in the waveform frequency spectrum.

\subsection{Sinusoidal PWM motor drive}

Measurements with a $4 \mathrm{kHz}$ sinusoidal PWM commercially available converter were also taken as shown in figure 18. There is a clear presence of the harmonics in the phase current due to saturation for the delta connection (figures 18c-18d). As observed in the simulation, the line current is free from the saturation harmonic.

Distorted phase voltage is observed in the measurement shown in figure 19 for the star connected motor, confirming the predicted by simulation.

Finally the measurement for the operation with voltage boost is shown in figure 20a. A V/f $20 \%$ higher than rated ratio was applied to the motor. Measured results are quite in accordance with those predicted by saturated model, as show in fig. 15. 


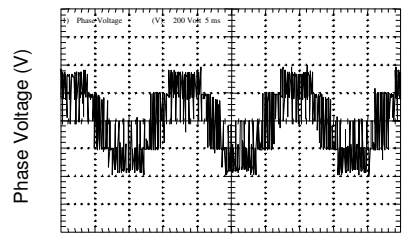

Time(s)

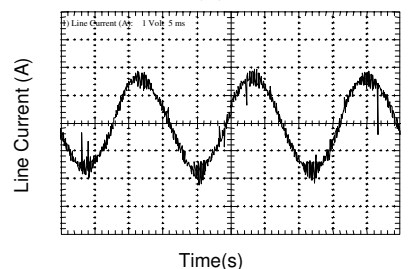

(c)

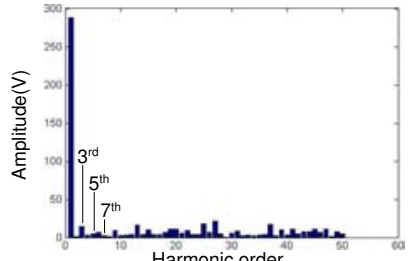

(b)

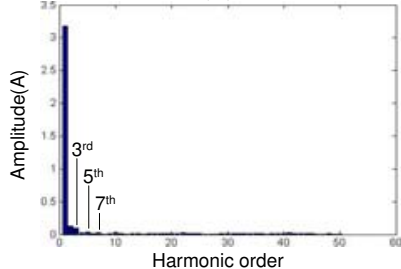

(d)
Figure 19: Results for star connection. (a) Phase Voltage; (b) Frequency Spectrum; (c) Line Current; (d) Frequency Spectrum.

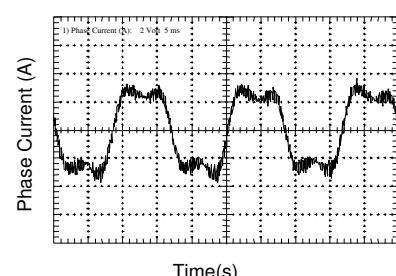

(a)

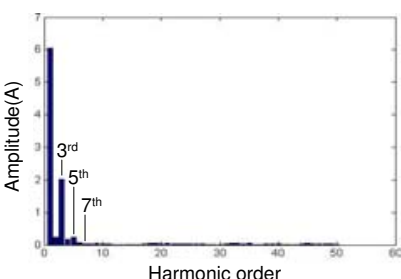

(b)
Figure 20: Operation with voltage boost. (a) Phase Current (delta connection); (b) Frequency Spectrum.

\section{CONCLUSIONS}

This work has presented a theoretical-experimental analyzis of the induction motor behavior fed by static converters considering the magnetic circuit saturation. Sixstep and sinusoidal PWM modulation techniques were studied and implemented for both delta and star winding connections. The comparison between the experimental and simulated results obtained with the nonlinear model shows very good agreement. Analyzes based on linear magnetic circuit are inherently inaccurate, since the harmonic components are not accounted for neither in the stator and rotor quantities nor in the electromagnetic torque. It was observed that the effects of the air gap flux harmonics are manifested in the phase currents for the delta-connected machine, while the phase voltages are affected when the machine is starconnected. In addition, saturation effects are also observed in rotor quantities and electromagnetic torque, as third-order harmonics in rotor currents and oscilla- tions in the motor torque.

\section{REFERENCES}

Bispo, D., et al., (2001). A New Strategy for Induction Machines Modeling Taking into Account the Magnetic Saturation. IEEE Transactions on Industry Applications. Vol. 37, $\mathrm{N}^{0}$. 6, pp. 1710-1719.

Khater, F. M., et al. (1987). Selection of Flux Level in Field-Oriented Induction Machine Controllers with Consideration of Magnetic Saturation effects. IEEE Transactions on Industry Applications. Vol. IA-23, $\mathrm{N}^{0} .2$, pp. $276-282$.

Levi, E. (1994). Applications of the current state space model in analyses of saturated induction machines. Electric Power Systems Research. Vol. 31, N0. 3, pp. 203-216.

Levi, E. (1996a). Main Flux-Saturation Modelling in dq Axis Models of Induction Machines Using Mixed Current-Flux State-Space Models. ETEP. Vol. 6, N0. 3, pp. 207-215.

Levi, E. (1996b). Main Flux Saturation Modelling in Double-Cage and Deep-bar Induction Machines. IEEE Transactions on Energy Conversion. Vol. 11, $\mathrm{N}^{0} 2$, pp. 305-311.

Liao, Y., et al. (1994). Effect of Saturation Third Harmonic on the Performance of Squirrel-Cage Induction Machines. Electric Machines and Power Systems. Vol. 22, pp. 155-171.

Melkebeek, J. A. A., et al. (1983). The Influence of Saturation on Induction Machine Drive Dynamics. IEEE Transactions on Industry Applications. Vol. IA-19, $\mathrm{N}^{0} 5$, pp. 671-681.

Moreira, J. C., et al. (1992). Modelling of Saturated ac Machines Including Air Gap Flux Harmonic Components. IEEE Transactions on Industry Applications. Vol. 28, $\mathrm{N}^{0} 2$, pp. 343-349.

Neto, L. M., et al. (1999). Analysis of a Three-Phase Induction Machine Including Time and Space Harmonics Effects: The A, B, C Reference Frame. IEEE Transactions on Energy Conversion. Vol. 14, $\mathrm{N}^{0} 1$, pp. 80-85.

Neto. L. M., et al. (1999). Magnetic Saturation Effect on a Three-Phase Induction Machines. IEEE SDEMPED'99 - International Symposium on Diagnostics for Electrical Machines, Power Electronics and Drives, Spain, pp. 1 - 3. 
Ojo, O., et al. (1994). Steady-State Performance Evaluation of Saturated Field Oriented Induction Motors. IEEE Transactions on Industry Applications, Vol. IA-30, $\mathrm{N}^{0} 6$, pp. 1638-1647.

Resende, J. T. (1999). Modelagem da Máquina de Indução Trifásica, incluindo a Saturação Magnética - Análise Dinâmica do Gerador de Indução AutoExcitado. Tese de Doutoramento, UFU, Uberlândia.

\section{APPENDIX I - MOTOR PARAMETERS}

Table 1: Induction Motor Data.

\begin{tabular}{|l|l|}
\hline Output rated power & $1.5 \mathrm{~kW}$ \\
\hline Rated speed & $1720 \mathrm{r} / \mathrm{min}$ \\
\hline Line voltage $(\Delta / \Upsilon)$ & $220 / 380$ Volts $\mathrm{rms}$ \\
\hline Stator resistance & $3,11 \Omega$ \\
\hline Rotor resistance & $3,83 \Omega$ \\
\hline Stator leakage inductance & $8,4 \mathrm{mH}$ \\
\hline Stator leakage inductance & $8,4 \mathrm{mH}$ \\
\hline Magnetization inductance & $127 \mathrm{mH}$ \\
\hline Rotor inertia & $0.0074 \mathrm{Kg}-\mathrm{m}^{2}$ \\
\hline
\end{tabular}

